\title{
LA COLECCION DE PINTURA COLONIAL DEL ATENEO FUENTE, EN LA CIUDAD DE SALTILLO, COAHUILA
}

Rogelio Ruíz GoMAR

Una muy grata e inesperada sorpresa aguarda al amante de nuestras expresiones plásticas en la visita al Ateneo Fuente, de la Universidad Autónoma de Coahuila, en la ciudad de Saltillo, en virtud de que ahí se guarda una colección de pintura interesante en verdad, y muy poco conocida. ${ }^{1}$

Dicho acervo es especialmente rico en ejemplos del quehacer pictórico, mexicano del siglo XIX y del primer tercio del XX. Pero cuenta también con material digno de la atención de los estudiosos e interesados en la pintura mexicana del periodo virreinal, y aun con aislados ejemplos de diversas escuelas europeas.

Gracias a la invitación y al apoyo del ingeniero Jesús Santos Méndez, actual Director del Ateneo, y a la amable insistencia de la arquitecto Leticia Sifuentes, responsable de las colecciones del mismo, hice un viaje a Saltillo los últimos dias del mes de septiembre del pasado año de 1988, a fin de conocer la colección y poder asesorar en la organización del lote de pintura correspondiente al periodo colonial, cuya existencia, debo confesarlo, hasta ese momento sencillamente ignoraba.

Resultado de esa visita son estas líneas que no tienen otro propósito que el de llamar la atención sobre el modesto, pero interesante, lote de cuadros novohispanos que ahí se guarda; cuanto más que, por formar parte de una colección muy poco conocida, dicho lote no ha sido debidamente valorado.

Antes de entrar de lleno en él, convendría apuntar algunas generalidades en torno a la colección. Así, no obstante que falta mucho por esclarecer en lo tocante al proceso de su formación, se acepta comúnmente

1 Fundado en el año de 1867 , el Ateneo Fuente pronto adquirió prestigio y se convirtió en un centro que habría de ejercer enorme influencia en la vida cultural del norte del país $y$, en especial, en la del Estado de Coahuila; al punto de que cuando, ya en este siglo, se creó la Universidad de dicho estado, se constituyó en la piedra angular de la misma. Debe su nombre al destacado licenciado Juan Antonio de la Fuente, quien representara a Coahuila ante el Congreso de la Unión, en 1840, y fuera miembro del Congreso Constituyente de 1856 y 1857. Ocupó, asimismo, las carteras de Relaciones, de Gobernación, de Hacienda y de Justicia, y fue ministro plenipotenciario en Francia. 
que el núcleo principal provino de los fondos de la antigua Academia de San Carlos, o Escuela Nacional de Bellas Artes, nombre con el que a partir del último tercio del siglo pasado se designó a aquella institución. ${ }^{2}$

Si ello fuera cierto, habría que pensar que dicho conjunto de obras fue enviado a aquella ciudad hacia la segunda década del presente siglo, cuando las autoridades de la Escuela no encontraron otro camino mejor para desembarazarse de las pinturas que ya no les interesaba conservar y que ya no cabían en las salas y bodegas - tanto del periodo colonial, como de algunas hechas por los propios maestros o alumnos, y aun algunas de artistas europeos-, que dividirlas en lotes y enviarlas al entonces Museo Nacional de Historia y a diversos Estados del interior del país. ${ }^{3}$ Sólo queda abrigar la esperanza de que algún día aparezca — si existe- la documentación oficial de dicho traslado o, en su caso, la información hemerográfica correspondiente, que permita corregir o avalar esta sospecha.

No está de más precisar, sin embargo, que otra importante y reciente vía en la conformación de la colección de pintura colonial que hoy día guarda el Ateneo Fuente, ocurrió a raiz de que quedaron incorporados al acervo las piezas reunidas por don Artemio de Valle Arizpe. ${ }^{4}$

Ahora bien, como ya se ha apuntado, el lote de cuadros del periodo virreinal con que cuenta la colección es bastante reducido. Su número no llega a la veintena de obras; y aún cabría precisar que en dicho número están contados tres cuadros que, en sentido estricto, no deberían considerarse aquí, porque rebasan el tiempo histórico del México colonial, pero que, por exhibir más nexos con la pinturá virreinal que con la academicista del siglo XIX, he preferido incluir en esta revisión; y, asimismo,

2 La relación se antoja casi obligada para con las pinturas del siglo XIX -en especial con las ejecutadas por los artistas que actuaron dentro de la Academiay bastante atractiva para con las obras europeas; pero creo que, sin forzar demasiado las cosas, se podría hacer extensivo el mismo origen a los cuadros del periodo colonial. Independientemente de que, como sabemos, en aquélla se guardaba abundante material de dicho periodo, ya tendremos oportunidad de confirmar tai procedencia, al menos, para un cuadro.

3 Vid. Fausto Ramírez Rojas, "Tradición y modernidad en la Escuela Nacional de Bellas Artes. 1903-1912", en Las Academias de Arte (VII Coloquio Internacional en Guanajuato), México, UNAM, IIE, 1983, pp. 248-249.

4 En efecto, a la muerte de don Artemio (1961), se decidió pasaran al Ateneo Fuente, institución que ya para entonces había quedado incorporada a la Universidad Autónoma de Coahuila, además de la biblioteca, algunos muebles, pinturas y diversas pertenencias del célebre y prolífico escritor. Y es que, no está de más recordarlo, éste, al igual que otros destacados hombres de letras, como Julio Torri y los hermanos Miguel y Vito Alessio Robles, había sido alumno del Ateneo. 
eliminar quizá otros dos que me inclino a pensar son de artistas novohispanos, aunque un estudio más detenido pudiera revelar que son, en realidad, obras europeas.

Asimismo, convendría adelantar que las más de dichas obras son anónimas y exhiben una calidad punto menos que mediana. Pero, justamente por ello, se hace más urgente y significativo el destacar que entre ellas encontramos, también, pinturas signadas por artistas de la talla de Juan Rodríguez Juárez, Miguel Cabrera, Patricio Morlete Ruiz y José de Páez. Hecho que no debe minimizarse, por cuanto que, la verdad, no todos: los días tenemos la fortuna de conocer nuevos cuadros de éstos o de cualesquier otros pintores de la plástica virreinal, así fuera para únicamente incorporarlos a los catálogos que se van armando de su producción.

Antes de pasar a la revisión de las obras en cuestión quisiera hacer una última aclaración. Para la presentación y organización del material adopté el criterio cronológico, por considerar que éste era tan válido como cualquier otro y porque me pareció que era el que metodológicamente ofrecía mejores posibilidades de estudio; y ello no obstante que soy consciente de que la muestra no da cuenta de todo el proceso que siguió la pintura en la Nueva España. ${ }^{5}$ Hubiera podido organizarse también en atención a los autores o a los temas que tratan, pero, en virtud de que, como hemos dicho, son más los cuadros anónimos que los firmados y de que entre ellos no existe mucha variación temática, me pareció más apropiado seguir el criterio cronológico, amén de que, a título personal, éra el que me resultaba más cómodo.

Así, la obra que encabeza la muestra, por más que no estoy del todo seguro sea obra novohispana, es una lámina de cobre en la que está representado San Juan Bautista predicando ( $73 \times 58.5 \mathrm{cms}$.), misma que exhibe un indudable acento manierista y en la que privan, de modo particular, notas de la escuela flamenca del siglo XVI.

Entre las notas que apoyarían la posibilidad de que hubiese sido hecha por un pintor europeo, resalta el interés y la calidad en la representación del bello paisaje que, en distintos planos, termina por envolver la escena. Es tal la amplitud e importancia concedida a éste, y las frondas de los árboles están trabajadas con tal esmero y exactitud, que, la verdad, se antoja muy difícil pensar que su autor hubiese sido alguien formado exclusivamente en el cerrado ámbito novohispano. En contraparte, el tra-

5 Pero la verdad es que, como ocurre en todo acervo y en todo museo, siempre habrá lagunas insalvables y obvias faltantes en el discurso históríco que se intenta cubrir. 
tamiento acartonado de las telas o el tipo de algunas de las figuras que aparecen congregadas en la parte baja, presentan cierta similitud con soluciones que perfectamente pueden adscribirse a la pintura que se practicaba en México hacia el primer tercio del siglo XVII. En esa misma dirección apuntan otros elementos, como el resplandor que ostenta San Juan, hecho con base en finos rayos dorados, o el tipo de algunas figuras. De manera particular quisiera llamar la atención sobre los tres personajes que aparecen en el ángulo inferior derecho, en los cuales creo percibir tanto ecos echavianos, como de la manera de ese otro pintor novohispano que fue Pedro del Prado; ${ }^{6}$ y señalar que el tipo que presenta esa mujer con su hijo, casi al centro, no puede menos que asociarse con el que encontramos en los lienzos que forman parte del retablo mayor del templo de San Francisco en Tlaxcala, hoy elevado a catedral, cuyo autor sigue siendo una incógnita por resolver, o en pintura como las de La Visitación y de Santa Ana con la Virgen niña, ambas indebidamente atribuidas a Luis Juárez en la Pinacoteca Virreinal de San Diego, en la ciudad de México.

Difícil me resulta pronunciarme por una u otra opción, pero sea europea o sea novohispana, lo cierto es que se trata de una de las piezas más tempranas y más atractivas de la colección.

De aquí se brinca la muestra hasta la segunda mitad del siglo XVII, época de la que cuenta, también, con un solo ejemplo. Se trata de una tela de modestas dimensiones ( $74 \times 49.5 \mathrm{cms}$.) que representa una Adoración de los pastores. Ostenta firma, pero su autor sigue sin identificar, porque dicha rúbrica resulta ilegible. Mas, quien haya sido, el trabajo que exhibe en el drapeado de las telas y en el manejo de la luz, revela a alguien que ha asimilado las calidades zurbaranescas, mismas que no se pusieron en boga en nuestro medio sino hasta mediados de dicha centuria. Cabe advertir, sin embargo, que mientras que el tipo empleado para San José y la Virgen se antoja típicamente novohispano, no ocurre lo mismo con el de los pastores, que acusan una factura un tanto más realista.

De finales del XVII y principios del XVIII encontramos tres cuadros sobre tela. El primero de ellos, obra de buenas dimensiones (216 x 147

6 Pintor que permaneciera en el olvido hasta hace muy poco, y de quien sólo conocemos las pinturas que decoran los retablos laterales de la pequeña iglesia de Santa Bárbara Tlacatempan, en el Edo. de México, muy próxima a Cuautitlán y Tepotzotlán; vid. Xavier Moyssén, "Pedro A. Prado, un pintor del siglo XVII" en Anales del IIE, núm. 40, México, UNAM, 1971, pp. 43-49. 
cms.) representa, al parecer, a San Francisco de Borja ${ }^{7}$ éste, hombre de mediana edad y vestido con la negra indumentaria de los jesuitas, aparece arrodillado hacia un lado de la composición, con un bello giro en el cuerpo y la mirada dirigida hacia la entrada de gloria que queda en el ángulo superior derecho, en la que se encuentra Jesucristo, semidesnudo y a menor escala, sentado entre nubes y rodeado de querubines.

En su calidad de tercer propósito general de la Compañia de Jesús, tocó en suerte a Francisco de Borja ser el fundador de la primera provincia de los jesuitas en la Nueva España. La corona que vemos en el suelo, así como el vistoso medallón, los collares que le cubren prácticamente el pecho y el cinturón que lleva, todo ello de oro con piedras preciosas, nos recuerdan la noble estirpe de éste (marqués de Lombay y duque de Gandía) antes de ingresar a la Compañia. Del mismo modo, el sombrero cardenalicio que también aparece en el suelo, nos indica la renucia que hiciera de tan alta dignidad eclesiástica.

Pese a que el cuadro ha sido reentelado, no luce en buen estado de conservación. Con todo, se impone al espectador la notable calidad de dibujo, así como lo agradable del colorido y el estupendo oficio con que están realizados el rostro y las manos del santo. La figura de Cristo, en cambio, se antoja blanda y convencional. Por otro lado, el cuidado que se advierte en la factura del medallón, los collares y el cinturón, nos deja ver la buena disposición, pero más aún el deleite con que los artistas del último tercio del XVII trabajaron las joyas.

Con muy leves variantes, este cuadro sigue el esquema compositivo del lienzo que por casi esas mismas fechas y con el mismo asunto hiciera Juan Correa; ${ }^{8}$ dato que permite inferir la existencia y circulación de un grabado o estampa que fue utilizado como modelo común por ambos artistas.

El segundo cuadro representaba el Martirio de Santa Bárbara (190.5 $\times 127 \mathrm{cms}$.). Se trata de una obra no exenta de interés, pero de menor

7 Así lo sugieren los atributos con que aparece; pero no está de más señalar que, a juzgar por el rostro que presenta, cuyo tipo empleado se aleja bastante del que estamos acostumbiados para San Francisco de Borja, bien pudiera pasar como una representación de San Francisco Javier o de San Cayetano.

8 Obra que se encuentra en las bodegas del Museo de Churubusco (INAH) en la ciudad de México. Vid. Efraín Castro Morales y Armida Alonso Lutteroth, Churubusco Colecciones de la iglesia y ex-convento de Nuestra Señora de los Ángeles, México, INAH, 1981 (Serie de Catálogos de la Dirección de Monumentos Históricos 1), p. 231; y Elisa Vargas Lugo y José Guadalupe Victoria, Juan Correa. Su vida y su obra t. II, Segunda Parte, México, UNAM, IIE, 1985, p. 313; cuadro núm. VII. 28-A. 
mérito que la anterior. Entre los aciertos que presenta merece destacarse el contraste que logró establecer el anónimo pintor entre los protagonistas de la escena, al entregarnos, por un lado, la delicada figura arrodillada de la santa, que espera con ánimo sereno y confiado el momento en que ha de entregar su alma al Creador, y, por el otro, al sayón o verdugo que, en dinámica postura, se dispone a asestar el golpe con que habrá de cortar la cabeza de aquélla; además, el de la suave expresión que alcanzó en el rostro de la primera y la fiereza en el del segundo, en el cual, por cierto, se sienten ecos de Cristóbal de Villalpando. Obra efectista pero que, bien mirada, se advierte llena de incorrecciones y debilidades; así por ejemplo, podemos señalar la involutariamente cómica falta de proporción en las figuras: excesivamente alargadas las de la santa y el verdugo, lo que hace que se vean como gigantes, y las muy empequeñecidas del Padre Eterno y Jesucristo en la entrada de gloria, que les confiere un grotesco aspecto de enanitos. Con todo, el cuadro se salva gracias al atinado trabajo de las telas, a la vivacidad de los colo. res y, sobre todo, a la sinceridad con que está plasmada la escena. El cuadro procede de la colección de don Artemio de Valle Arizpe.

Finalmente, el tercer cuadro de este grupo representa a Santa Rosa de Lima $(150 \times 105 \mathrm{cms}$. $)$; obra que participa de ese sabor fresco e ingenuo que distingue al llamado arte popular, tanto por la manera esquemática y plana de trabajar los rostros y manos, como por el tipo de los angelitos y por la torpeza con que están resueltas las posturas. Aparece la santa arrodillada, vestida con el hábito dominico y su cabeza ceñida con una corona de espinas; porta unas rosas en un pliegue del escapulario, del que ya ha sacado una, que ofrece al niño Jesús, quien, sentado en las piernas de su madre y luciendo una corona de rosas, la bendice.

Esta obra resulta difícil de fechar, pero acaso pueda ubicarse en años cercanos al de 1681 en que, como sabemos, fuera canonizada ésta la primera flor de santidad del mundo americano. Quizá esto explique, también, lo atípico de su nombre en la inscripción: "Santa Rosa de Santa María". El escudo con las tres coronas y la estrella que vemos a espaldas de la santa corresponde al de la ciudad de Lima, Perú, la que, por haber sido fundada un 6 de enero, fue bautizada como "la ciudad de los Reyes"; aquéllas significan, pues, las coronas de los tres reyes magos y la estrella de Belén. Llama la atención el hecho de que la Virgen aparezca sin velo, lo que permite que su larga y rubia cabellera caiga en amplias ondas sobre cuello, hombros y espalda. También este cuadro proviene de la colección de don Artemio. 
Del primer tercio del siglo XVIII cuenta el Ateneo Fuente con un magnífico ejemplo. Se trata de un lienzo en el que aparece San Pedro con el rostro desnudo, dentro de un óvalo fingido y sobre un fondo oscuro $(126 \times 102 \mathrm{cms}$.). Inspirado cuadro signado por Juan Rodriguez Juárez -el célebre autor de las pinturas que se alojan en el retablo de la capilla de los Reyes en la catedral metropolitana- que no puede uno menos que relacionar con los lejanos modelos de José de Ribera, el Españoleto, por más que no exista entre éste y aquéllos más coincidencia en el uso de ciertos recursos plásticos: cruda recreación del desnudo de un anciano realzada por un manejo efectista de la luz. El cuerpo del "Príncipe de los apóstoles" sigue un violento giro que se inicia en la cabeza, la cual queda de perfil y vuelta sobre el hombro izquierdo, y termina en las manos entrelazadas en el costado derecho, a la altura de la cadera. La figura marca así un eje diagonal que imprime tensión al personaje y alivia algo la severidad y sequedad de la composición. La vital y novedosa postura del santo se enriquece y contrasta con la que guarda el niño (¿angelito?) que aparece hacia el ángulo inferior derecho mostrando al espectador una estampa en la que está representado el martirio del propio San Pedro. Lo anguloso de las formas anatómicas de aquél se transforman en suaves curvas en la figura de éste, la que se antoja igualmente dinámica, pero articulado con base en una cadencia más armónica. Por otro lado, parece oportuno señalar que precisamente al pie de aquella estampa el artista colocó su firma "Joannes Rodríguez Xuarez inven" et pinc.",, pero más aún llamar la atención sobre esa franca postura de autoestima y de legítimo orgullo de parte del artista que se manifiesta desde la firma, al hacernos saber que él, además de ser el autor material de la pintura, fue el "inventor" de la composición. Interesantísina pintura, en verdad, en la que la luz juega un papel fundamental. A nadie escapa que la fuerza plástica que anima a las dos figuras proviene, en muy buena medida, del vigoroso modelado con que están trabajadas sus carnes; modelado conseguido, a su vez, por el magistral claroscuro de que hace gala el pintor en este cuadro: efectos lumínicos que, ni duda cabe, coadyuvan a imprimir dramatismo y vitalidad al mismo. Tengo para mí que Juan Rodríguez Juárez alcanzó aquí uno de sus claroscuros más intensos y mejor logrados.

Pero sigamos adelante. El grupo más nutrido e importante de la colección está constituido por las obras de mediados del siglo XVIII. Podemos empezar con la Inmaculada concepción, trabajada sobre lámina de cobre, en la que aparece María dispuesta sobre un fondo de color amarillento, 
con un delicado giro en el cuerpo, la mirada baja y las manos recogidas sobre el pecho. Quizá debido al hecho de que se advierten en ella ecos de las célebres "Inmaculadas" de Murillo, tanto en la actitud de María, como en la postura de algunos angelillos, y al tamaño de la lámina en que está trabajada $(63.5 \times 49 \mathrm{cms}$.), cuyas dimensiones son más grandes que las que solían emplear los artistas novohispanos, es que se la tiene registrada como pintura de la escuela española. Pero más me inclino a pensar que es obra realizada por algún maestro activo en la Nueva España. Al respecto cabe recordar que, precisamente hacia esas fechas, algunos pintores novohispanos, verbigracia Juan Patricio Morlete Ruiz, trabajaron en láminas de esas dimensiones.

Indudable mérito tiene el pequeño cuadro sobre tela que representa a Santo Domingo de Guzmán $(37.5 \times 31 \mathrm{cms}$.), y que da la impresión de ser fragmento de una composición mayor, hoy perdida. En efecto, el que aparezca sólo la cabeza del santo, casi de perfil y con la mirada hacia lo alto, así como el que precisamente hacia esa zona se aclaren las nubes, permite inferir que la escena continuaba y que el santo era distinguido con una visión celestial. Si ello era así, acaso la escena representaba el momento en que la Virgen le entregaba el rosario.

En la parte posterior tiene un sello por el que sabemos que era "Propiedad de la Escuela Nacional de Bellas Artes" —éste es, pues, el único cuadro del que podemos afirmar, con toda certeza, que salió de las colecciones de la Academia-; pero el que dicho sello aparezca completo, parece indicar que, si como pensamos, lo que ha llegado a nosotros es sólo un fragmento, la mutilación practicada al lienzo original no es reciente pues que data, al menos, de cuando estaba en aquella institución.

Entre los cuadros más importantes de la colección está el de la Inmaculada concepción, firmado y fechado "Martínez año 1759" $(125 \times 99$ cms.); lienzo de forma ovalada en el que aparece María flanqueada por unos angelillos que sostienen dos escudos iguaimente de forma oval: uno con la representación de los brazos cruzados de Jesús y de San Francisco de Asís, y el otro con la cruz de Malta, grande, en cuyos ángulos se alojan otras cuatro cruces idénticas a la primera pero más pequeñas. Por último, se aprecia un tercer escudo con las cinco llagas de Cristo, al centro en la parte baja, mismo que adopta forma de frijol, y queda enmarcado por el cordón franciscano.

Por todo lo anterior, casi resulta obligado concluir que el cuadro fue encargado para decorar una casa de la orden franciscana; y es que no sólo esta religión fue una de las que más se distinguió en la defensa de 
la pureza de María, sino que con ella están relacionados los emblemas mencionados y el cordón que enmarca al tercero de ellos. ¿Tendrán éstos algo que ver con las tres ramas de la familia franciscana?

Respecto del artista, sabemos que se apellidaba Martínez y que estaba activo hacia mediados del XVIII. Esto, aunado a las características de dibujo y color, el tipo de los rostros y el manejo de las telas, pudieron tomarse como notas que apuntan en dirección de Francisco Martínez, aquel desigual pintor que también se desempeñara como dorador, y que fuera, igualmente, notario del Santo Oficio. ${ }^{9}$ Pero, o existe un error en la lectura de la fecha o habrá que convenir en que se trata de otro artista, toda vez que Francisco Martínez murió en 1757, y este Martínez, como vemos, trabajaba aún dos años después.

Del celebérrimo pintor oaxaqueño Miguel Cabrera, cuyo sólo nombre ha eclipsado al de la mayoría de los demás pinceles novohispanos, se guardan en la colección dos cuadros, a los que se podría añadir otro que se le ha querido atribuir. Los firmados por tan egregio maestro son una tela con la Adoración de los pastores y una lámina de cobre con San Pablo. El primero es un lienzo de forma oval $(95 \times 71.5 \mathrm{cms}$. $)$ que ni con mucho pudiera considerarse entre las mejores obras salidas de su prolífico pincel. Cabe señalar el acertado claroscuro que consiguió al intentar sugerir que la fuente de la luz de la escena irradia del cuerpecillo del niño Jesús, casi al centro de la composición, pero entre las debilidades que exhibe hay que reconocer, por ejemplo, que los angelillos de la parte superior están muy lejos de la calidad a que este pintor nos tiene acostumbrados. Del mismo, las telas muestran una factura descuidada y los rostros se antojan estereotipados y un poco duros. ¿Tales notas pueden explicarse aduciendo que estamos ante una obra en la que el maestro aceptó una amplia intervención de los oficiales que le auxiliaban; esto es que se trata de una obra de taller? Así pudiera ser, en efecto; empero, acaso también pudiera esgrimirse el no menos trillado pero igualmente válido argumento de que se trata de una obra temprana dentro de su producción.

Por su parte, la lámina que representa a San Pablo ostenta la fecha de 1762. Se trata, pues, de una obra de madurez. Y aunque para ese entonces Cabrera estaba seguramente agobiado de encargos, para cuyo cumplimiento se vería obligado a contar con el auxilio de los miembros de

9 Recuétdese que él fue el responsable de dorar el Retablo de los Reyes de la catedral de México en 1743, así como los retablos de la capilla de Zuleta en el templo de San Francisco México, y de varios más. 
su taller, no podemos sino reconocer la notable calidad pictórica que encierra esta obra que, curiosamente, también es de forma oval $(64 \times 48$ cms.). El "Apóstol de los gentiles" aparece casi de frente y con la mirada dirigida hacia el espectador, sobre fondo oscuro y visible hasta la cintura. Sujeta una espada con la mano derecha mientras descansa la izquierda sobre un libro. Viste túnica de color café oscuro y un manto rojo. Pero es esa fuerza que imprimió Cabrera a su rostro lo que más nos impresiona; rostro que exhibe gran correción en el dibujo y un magnífico sombreado. No exageramos si decimos que en muy pocas ocasiones el propio Cabrera alcanzó tal elevada inspiración.

Estaba registrado como San Bartolo - seguramente se quería decir "San Bartolomé"-, pero, sin lugar a dudas, se trata de una representación de San Pablo: a él corresponde, además del tipo con que está plasmado, la inclusión de la espada y el libro, elementos que le son propios y que aluden a su carácter combativo, a la fuerza de su palabra y a sus Epistolas.

Cabe señalar que el rostro recuerda muchísimo al que usó el mismo Cabrera en otros cuadros, verbigracia, en el de San Anselmo, ${ }^{10}$ en el cual se ha querido ver un "autorretrato" del pintor, por la semejanza que guarda para con aquel otro cuadro que igualmente se ha venido manejando como Autorretrato de este pintor - aunque también de aquel otro afamado artista que fue José de Ibarra-, en la Pinacoteca Virreinal de San Diego.

El cuadro atribuido a Cabrera es uno que representa a San José con el niño $(151 \times 112 \mathrm{cms}$.), ejecutado sobre tela y que tiene asimismo forma oval. San José aparece sentado en un sillón de alto respaldo, con la mirada dirigida hacia el espectador y la cabeza apoyada en la del niño Jesús, quien se encuentra dormido en sus brazos. Viste la tradicional túnica verde y el manto sepia, sólo que ahora ambas prendas están decoradas con grandes motivos vegetales en dorado.

Se ha atribuido a Cabrera en virtud de la indudable semejanza que guarda con el cuadro por él firmado que, del mismo tema y composición, se custodia en el Museo Nacional de Historia, o Castillo de Chapultepec, en la ciudad de México. Pero he de advertir que así como puede adscribirse a Cabrera, puede hacerse lo mismo con cualquiera de los otros buenos pintores que florecieron hacia esa época, verbigracia, a José de Ibarra, Andrés de Islas, Francisco Antonio Vallejo o José de Alzibar, toda vez

10 Cuadro que pertenece a la Pinacoteca Virreinal de San Diego (INBA) de la ciudad de México, y ahora se exhibe en el Museo Regional de Oaxaca. 
que participa de esa suavidad y de ese tono dulzón que caracteriza a la producción pictórica novohispana de hacia mediados de la centuria decimoctava. En justicia, empero, habría que agregar que este cuadro presenta un colorido más encendido y contrastado, una pincelada más cuidada y un tratamiento de los paños más natural que la mayoría de las obras ejecutadas en esa época. Cabe señalar, por otra parte, la inclusión de un excelente "bodegón" en la vara de azucena y en la cesta con frutas que aparecen sobre la mesa, a un lado; trozo en el que se puede admirar la buena disposición que hacia este género poseía el anónimo pintor.

De la misma época es otro lienzo con la representación de San José con el Niño $(143.5 \times 108$ cms.). Es de forma rectangular, si bien los protagonistas quedan encerrados dentro de un enmarcamiento fingido que cierra en medio punto, pintado en gris y con las enjutas rehundidas y más oscuras, que en algún momento le fue agregado, pues pasa demasiado cerca de la cabeza de unos querubines y corta la punta de las alas de la paloma del Espíritu Santo. Aparece San José semiarrodillado sobre una nube, con el niño Jesús dormido en sus brazos y la mirada levantada hacia la paloma del Espíritu Santo que desciende sobre ellos. Al centro, en la parte baja, se aprecia una cartela dentro de un vistoso marco de ascendencia rococó, cuya inscripción no resisto la tentación de transcribir, por lo curioso de los datos que proporciona: "El Glorioso Patriarcha S. Joseph nació año de 5166 de la Creación del mundo, desposose con María Ssma. a los 33 años de su edad; murió a los 60 , después de ocho años de enfermedad, a los 27 de la edad del Señor".

Bella obra que comparte las notas señaladas para el cuadro anterior y que son comunes a la pintura de mediados del siglo XVIII; dibujo poco consistente, colorido armonizado en grises, azules y rosas; rostros de aspecto "bonito", de mejillas sonrosadas, y telas trabajadas a base de pinceladas sueltas y poco cuidadas.

Quizá el sencillo marco de madera que se le ha adaptado oculte la f́irma del pintor, pero podemos adelantar que el autor se siente cercano nuevamente a Cabrera, pero también algo a José de Ibarra y artistas como José de Páez de Alzibar en su fase temprana. El cuadro se encuentra en excelente estado de conservación.

Firmado por Juan Patricio Morlete Ruiz, se guarda en esta colección otra Inmaculada Concepción. Es un lienzo de forma oval $(150 \times 120$ cms.) en el que aparece María con la cabeza ligeramente inclinada, la mirada baja, las manos juntas a la altura del pecho y una rodilla flexio- 
nada. Despide su cabeza un resplandor de finos rayos dorados, con doce estrellas, y queda envuelta en una aureola azul, amén de otra aureola exterior formada por siete querubines. Luce un paño rojo a manera de diadema, pero el pelo cae suelto y con tanta amplitud que forma una auténtica cascada sobre hombros y espalda. Detrás de su figura se asoma un sol de rasgos humanos y alrededor de la misma quedan distintos símbolos de la letanía lauretana. Entre éstos destaca la torre almenada que se ve por el lado izquierdo (¿la de David?), misma de la que penden siete listones rojos que rematan, cada uno, en un sello de oro.

Obra de agradable efecto barroco, merced a la profusa decoración en dorado que ostentan la túnica y el manto y al vuelo de las puntas de éste, por más que no sea muy feliz la solución de que ambos extremos de él se levantan hacia el mismo lado. Por lo que toca a la dicha decoración en las vestiduras hay que apuntar que le confiere a la figura un efecto muy próximo al de una imagen de bulto trabajada con la técnica del estofado; nota, por otro lado, algo extraña entre los pintores novohispanos pero frecuente en los de algunas escuelas sudamericanas.

Se trata de una obra de Morlete Ruiz - ese buen pintor originario de San Miguel el Grande (hoy de Allende), que terminó avecindándose en la ciudad de México, y que se formó con José de Ibarra-, por más que la firma resulte atípica: "Joanes Patricius Ruiz fac"; esto, sumado a la mayor blandura en el tratamiento del rostro, las manos y las telas, y a que está ausente la gran calidad y corrección en el dibujo que distinguía a este pintor, acaso indique que se trata de una obra temprana dentro de su producción. El cuadro proviene de la colección de don Artemio.

De la segunda mitad del siglo XVIII se guardan dos obras: un lienzo de buenas dimensiones que representa a una Religiosa Concepcionista y otro más pequeño con el retrato de un jesuita. El primero, pese a sus dimensiones $(112 \times 145 \mathrm{cms}$.$) , parece ser fragmento de una composi-$ ción mayor. Vemos en él a una religiosa concepcionista que debió destacarse por su sabiduría y sus escritos, pues que se le ha representado sentada frente a su mesa de trabajo, con una pluma en la mano y sujetando un libro, al tiempo que tiene como fondo una estantería repleta de libros. Aparece la religiosa de tres cuartos perfil derecho y con la mirada levantada. Precisamente, el hecho de que aparezca con la mirada fija hacia un punto indefinido fuera del cuadro, permite inferir que algo falta; lo que se refuerza cuando advertimos que la arquitectura que se plasmó en ese extremo se altera hacia la parte superior.

En virtud de todo lo anterior y de que no luce aureola, se le tenía 
DOI: http://dx.doi.org/10.22201/iie.18703062e.1989.60.1547

1. San Juan Bautista. Oleo sobre la lámina de autor anónimo. ¿Escuela flamenca? Obra del paso del siglo XVI al XVII.

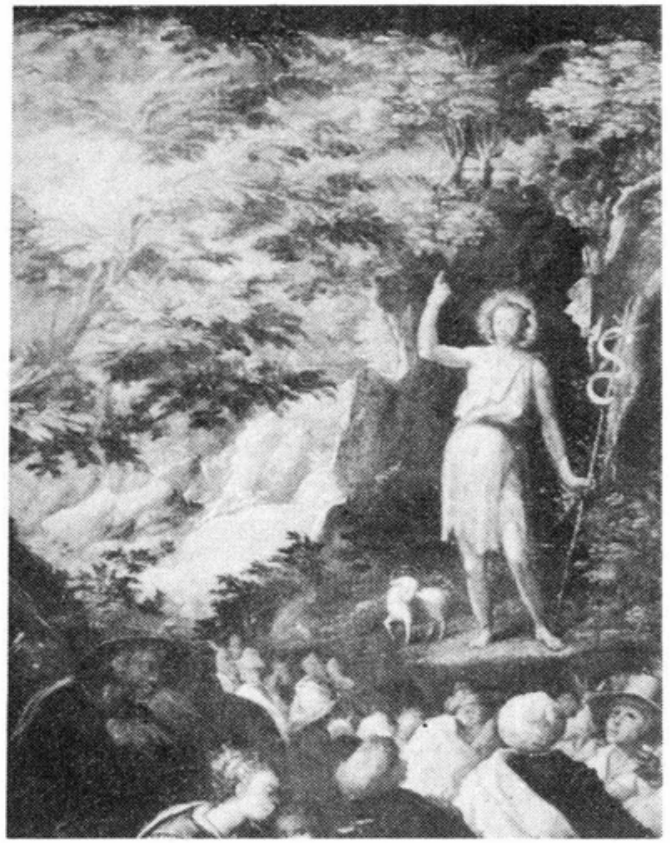

2. Martirio de santa Bárbara. Oleo sobre tela de autor anónimo. Obra del paso del siglo XVII al XVIII.

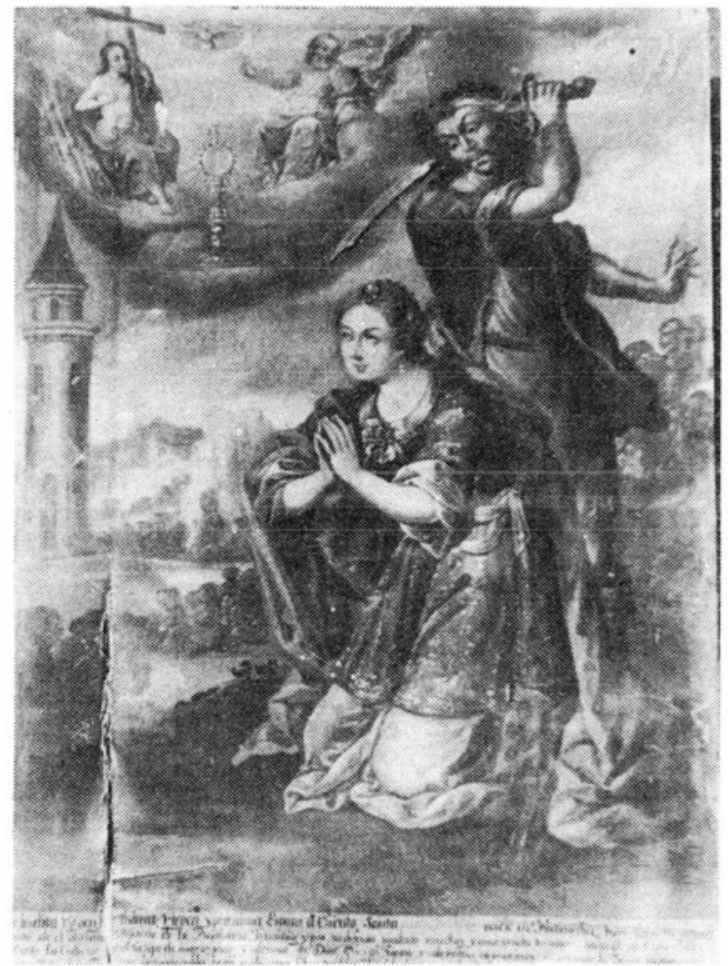


DOI: http://dx.doi.org/10.22201/iie.18703062e.1989.60.1547

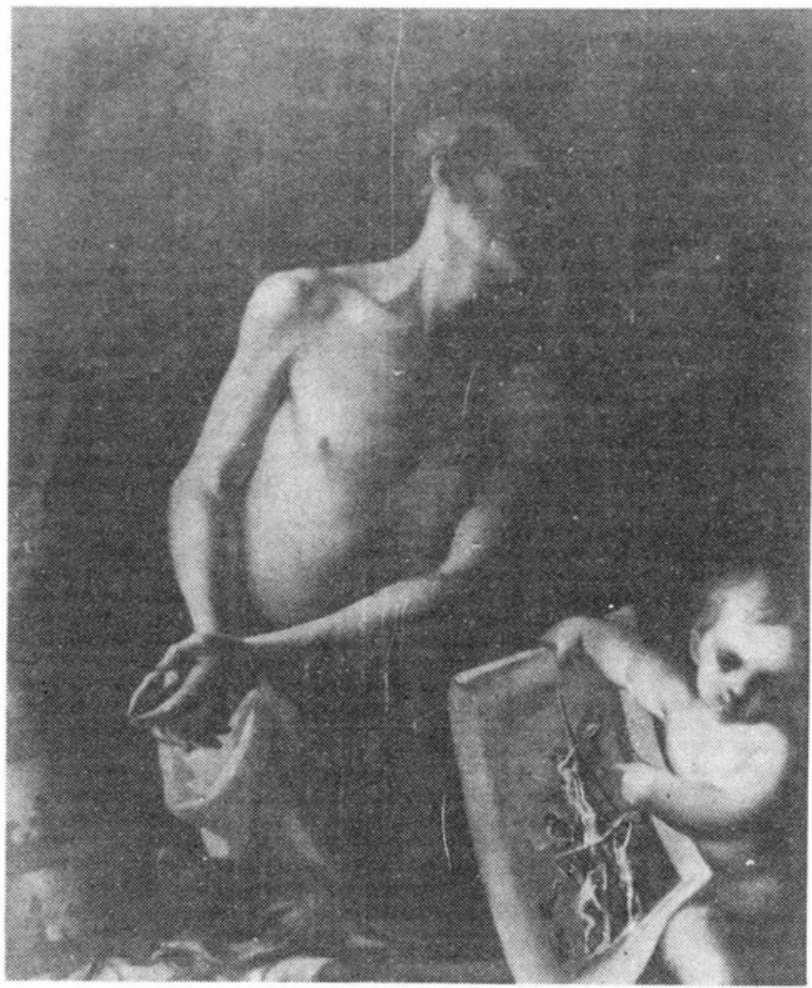

3. San Pedro. Juan Rodríguez Juárez. Oleo sobre tela del primer tercio del siglo XVIII.

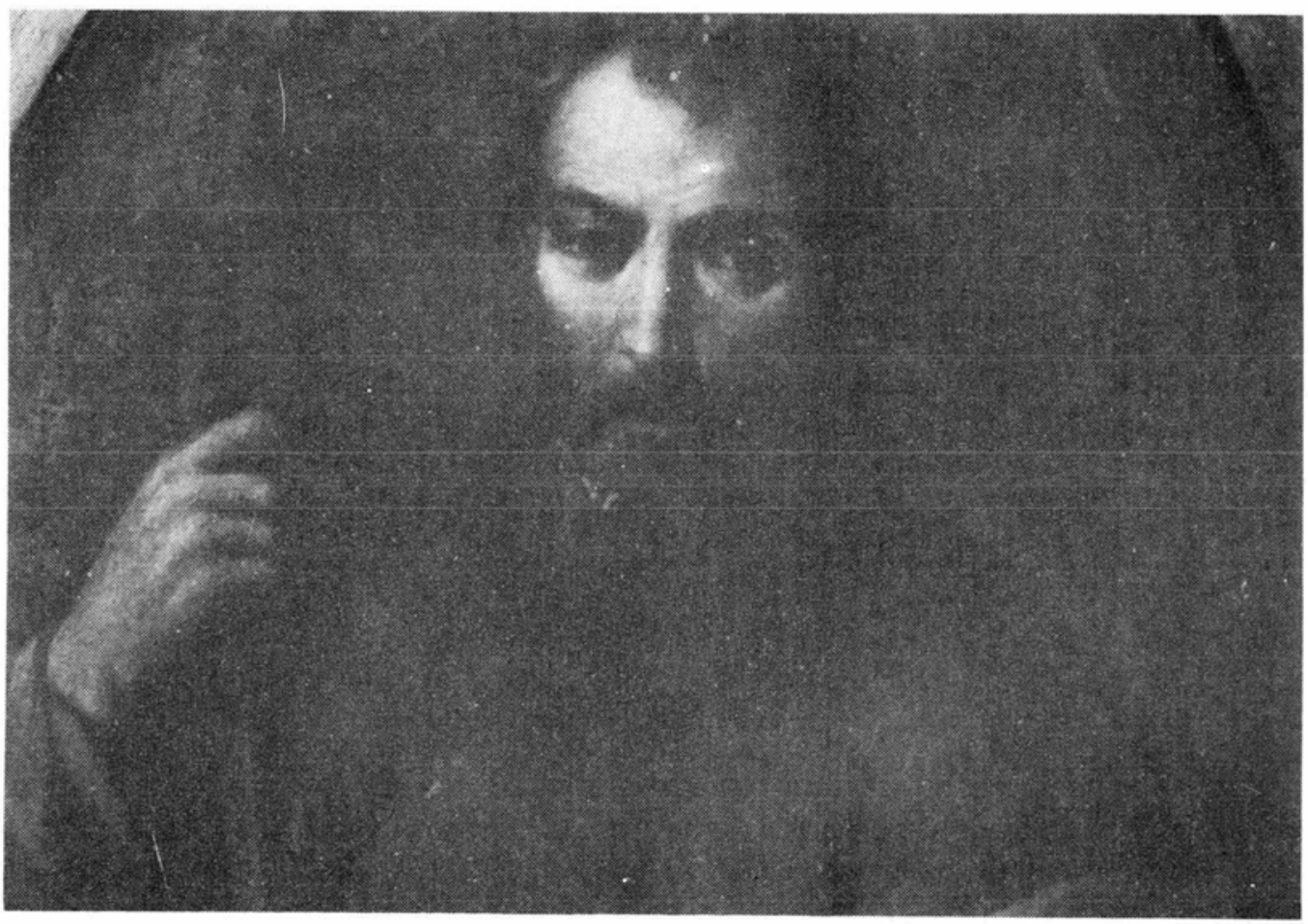

4. San Pablo. Miguel Cabrera. Oleo sobre lámina de cobre de mediados del siglo XVIII. Detalle. 
DOI: http://dx.doi.org/10.22201/iie.18703062e.1989.60.1547

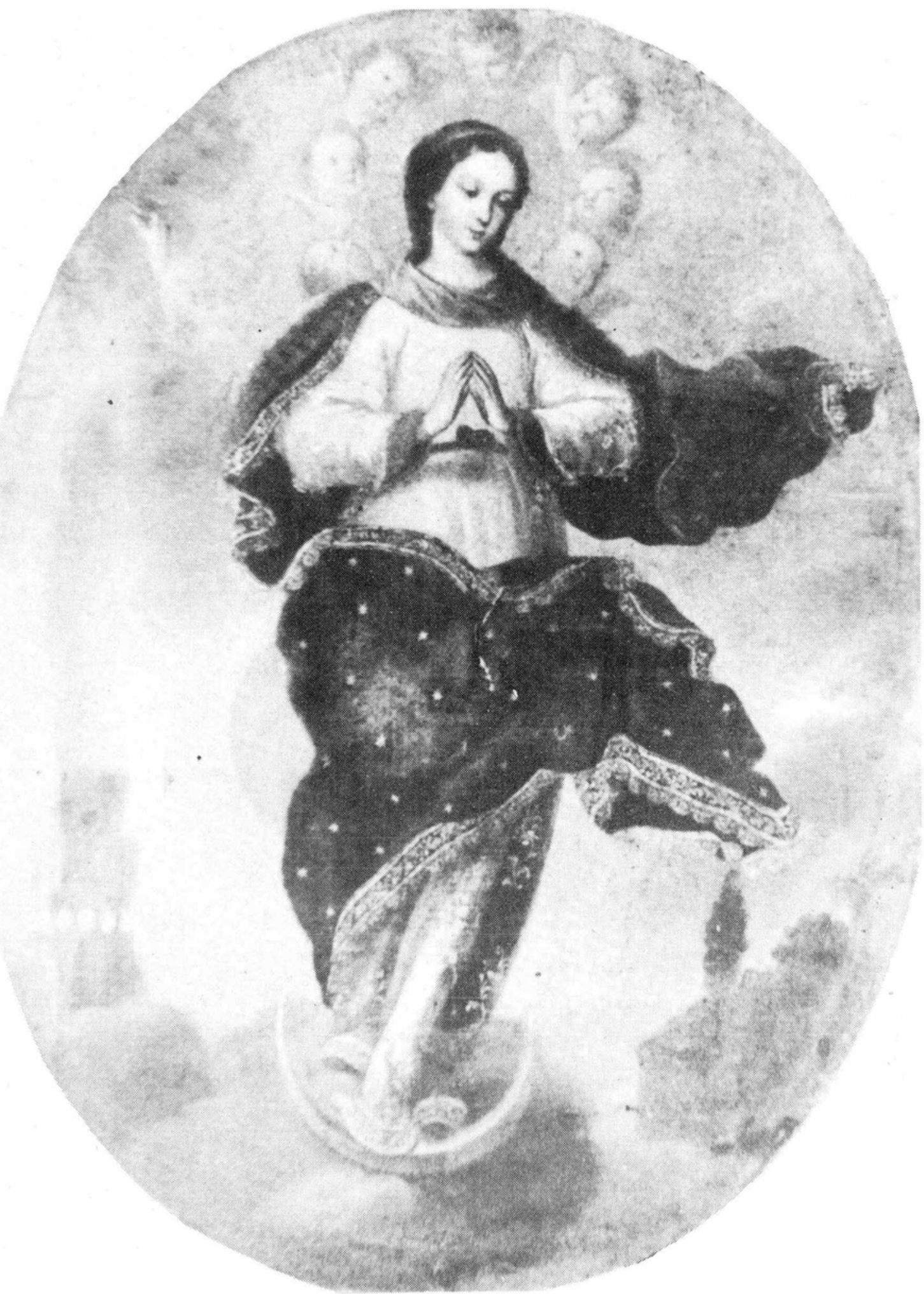

5. Inmaculada Concepción. Juan Patricio Morlete Ruiz. Óleo sobre tela de mediados del siglo XVIII. 
DOI: http://dx.doi.org/10.22201/iie.18703062e.1989.60.1547

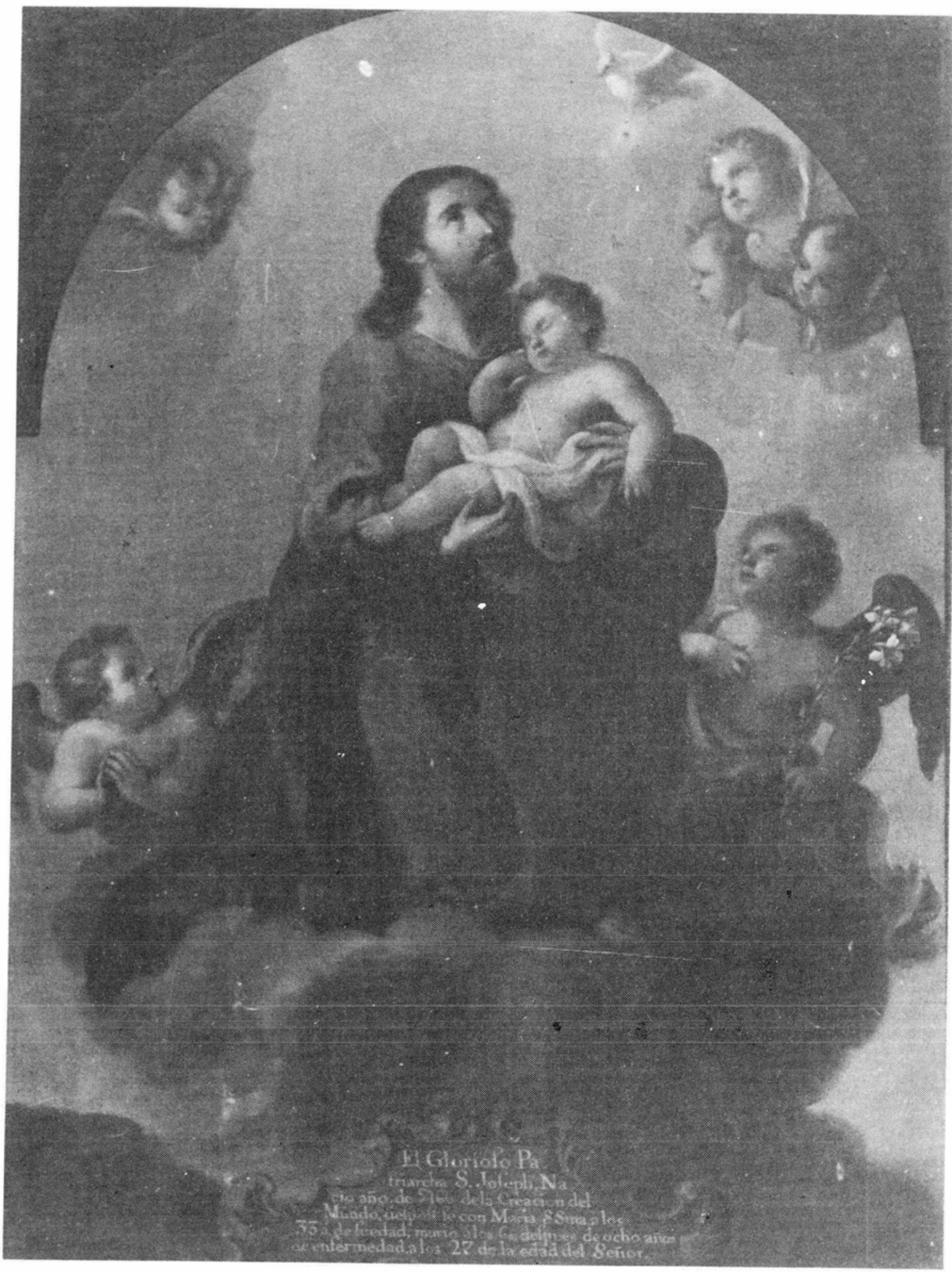

6. San José con el Niño. Oleo sobre tela de autor anónimo, de mediados del siglo XVIII. 
como representación de nuestra célebre poetisa y escritora sor Juana Inés de la Cruz Pero ésta era monja jerónima y la aquí representada hemos dicho que porta el hábito de las concepcionistas. Por ello cabe la posibilidad de que se trate de la afamada sor María de Jesús de Agreda, la visionaria española del siglo XVII, autora de la Mistica ciudad de Dios. Por otro lado, a juzgar por el lenguaje plástico cabreriano que exhibe, debe haber sido ejecutado por alguno de los artistas que florecieron a la sombra de aquél, cual pudiera ser el caso de Juan Patricio Morlete Ruiz, de Francisco Antonio Vallejo y de José de Páez, o incluso de José de Alzibar, en sus primeros años.

El otro cuadro es el Retrato del padre José Carrillo, quien, como nos informa la inscripción que corre en el borde inferior de la tela, fue "Director de la casa de Ara Coeli en la ciudad de México", El personaje aparece visible hasta la cintura y dentro de un óvalo fingido. Cubre su cabeza con un gorro negro y tiene la mirada dirigida hacia el espectador. Sobre el gris del fondo destaca una estampa clavada por sus esquinas con la representación del anagrama de Jesús "IHS", usado como escudo por la Compañía de Jesús.

Obra de indudable mérito que ostenta buena factura en rostro y manos, especialmente en el primero, conformado por ojos pequeños, enorme nariz y boca de finos labios; rostro en el que el artista alcanzó buena dosis de verdad. La firma del pintor se localiza al final de la inscripción: "Joseph de Paez pinxit"; si bien, resulta interesante advertir que aparece con grafía diferente a la de aquélla, y más pequeña.

En la colección del Ateneo Fuente encontramos, finalmente, un pequeño lote conformado por tres piezas que, realizadas en los primeros años del México Independiente, todavía están compuestas de acuerdo con la tradición barroca del período colonial. Curiosamente, los tres cuadros proceden de la colección de don Artemio de Valle Arizpe.

Podemos empezar con el lienzo que nos muestra la efigie de San Agustín, mismo que ostenta la firma de fray José Huerta y la fecha de 1829. Luce el obispo de Hipona el hábito negro de su orden, pero en su calidad de "Doctor" en Filosofía porta esclavina de color azul. Obra en la que, como se ha dicho, se puede advertir a un artista formado dentro del mundo barroco pero imbuido ya de los aires renovadores del movimiento neoclasicista. Así, la composición tiene liga con la pintura virreinal, pero en lo que toca al dibujo, al color, al cuidado de la pincelada y, claro está, a la decoración bordada en oro que presenta la mitra de seda branca, responde más al gusto del neoclásico. 
El triángulo con el ojo en su interior que se aprecia en el ángulo superior izquierdo, alude seguramente a la omniciencia divina, por más que este símbolo se haya empleado en forma más genérica para significar a la santísima Trinidad y aun para aludir exclusivamente al Padre Eterno. Sea como fuere, es una solución plástica de uso más frecuente en el gusto decimonónico.

De muy modesta calidad es un pequeño lienzo con la Imagen de Jesús $(71 \times 48.5 \mathrm{cms}$.) que seguramente es la transcripción pictórica de alguna escultura procesional de la época, pues que aparece aquélla flanqueada por cirios, sobre andas y debajo de dosel. Viste Jesús una amplia túnica de color negro con decoración de plata, a base de flores. Interesante es el marco moderno que la resguarda, en cuyo copete, con decoración calada, se ve el escudo de la orden de Nuestra Señora de la Merced.

El último cuadro es, de nueva cuenta, un tema mariano. No carece de interés artístico, pero lo que más nos atrae de él es lo curioso de la advocación: una representación de la Virgen de la Vida; bajo una bóveda casetonada, y sostenida por tres esbeltas columnas que representan a las virtudes teologales ( $\mathrm{Fe}$, Esperanza y Caridad), aparece la Virgen María acompañada por dos de los arcángeles más conocidos: Miguel y Rafael. ${ }^{11}$

Hemos llegado al final de esta rápida revisión. Como se habrá advertido, predominan los cuadros del siglo XVIII, pero cuenta la colección con atractivos ejemplos de distintas e importantes etapas de la centuria anterior y de tres ejemplos de principios del XIX. Temáticamente no encontramos novedades, toda vez que, a excepción del de la Virgen de la Vida, abarcan los asuntos más comunes de la plástica virreinal. Hay un predominio, pues, de cuadros de carácter religioso, y, dentro de estos, los más numerosos son los que se ocupan de la Virgen María (tres "Inmaculadas") y de asuntos de la infancia de Jesús (dos "adoraciones" de los pastores). Del mismo modo, hay cabida para la representación de algunos santos, entre los que destaca "San José", con dos versiones, pero también figuran San Francisco de Borja, Santo Domingo de Guzmán, Santa Bárbara y Santa Rosa de Lima. Cabe advertir que la representación de algunos de ellos puede obedecer a la devoción concreta de algún particular, pero no podemos descartar la posibilidad de que tratándose,

11 Curiosa advocación mariana que debe haberse introducido en México hacia la primera mitad del siglo XIX, pues que sólo conozco dos versiones de la misma, y ambas parecen datar de esta época. El otro cuadro se guarda en las bodegas del museo de Churubusco. Vid. Efraín Castro Morales y Armida Alonso Lutteroth, op. cit., p 214. 
también, de miembros destacados de determinados órdenes y comunidades religiosas (vgr. jesuitas y dominicos), éstas buscaran su exaltación mandándolos representar. Sea como fuere, el hecho es que a todos ellos se les debió utilizar como modelos a imitar y como eficaces intercesores ante Dios. ${ }^{12}$

Finalmente, como ejemplo del otro gran capítulo de la pintura novohispana, existe en la muestra un aislado pero aceptable retrato tomado del natural, amén del que suponemos es otro retrato, pero éste idealizado, de una religiosa concepcionista.

La mayoría de los cuadros son anónimos, pero vale la pena insistir en que no cualquier institución puede preciarse, como sí el Ateneo Fuente, de poseer un Rodríguez Juárez, un Morlete Ruiz y dos Cabreras.

A lo largo del recorrido encontramos obras de heterogénea calidad. Pero ni duda cabe que la colección cuenta con dos o tres cuadros extraordinarios; tales los casos del San Pedro de Juan Rodríguez Juárez y el San Pablo de Miguel Cabrera, que cualquier museo se enorgullecería de poseer.

Por último, podríamos calificar como regular el estado de conservación en que, en términos generales, se encuentra la colección; pues si bien para algunas obras podría recomendarse una pronta intervención, para otras, en cambio, habría que mencionar que lucen en perfecto estado.

Sólo resta congratularnos por la conformación de este interesante acervo y felicitar a los responsables de su custodia por la preocupación que de tiempo atrás, pero de modo más particular hacia las últimas fechas, han mostrado en torno a su cuidado y su difusión. Por mi parte, confío en haber contribuido con estas líneas a la valoración de la colección de pintura colonial que guarda el Ateneo Fuente y ayudado a despertar el interés de los conocedores y de todos' los amantes de nuestros valores culturales, para motivarlos a que, aprovechando un viaje a Coahuila, puedan disfrutar de la cordialidad que distingue a los habitantes de Saltillo y gozar con los cuadros reunidos en tan prestigiosa institución.

12 Tal es el caso de Santa Bárbara, la cual, como ilustra la inscripción que leemos en su cuadro: "pidió y alcanzó de Dios que los que fuesen sus devotos no murieran sin recibir los santos sacramentos", o caando, poco más adelante, se nos informa que "Libra también a los que la invocan de los rayos, centellas y tempestades". 